\title{
Improvement of Slow Wave Sleep Continuity by Mattress with Better Body Pressure Dispersal
}

\author{
Momoko Kayaba, $\mathrm{PhD}^{1,2}$, Hitomi Ogata, $\mathrm{PhD}^{3,4}$, Insung Park, $\mathrm{PhD}^{1,3}$, Asuka Ishihara, $\mathrm{BA}^{1,5}$, \\ Fusae Kawana, BSc, RPSGT ${ }^{1,6}$, Toshio Kokubo, $\mathrm{PhD}^{1}$, Shoji Fukusumi, $\mathrm{PhD}^{1}$, Michiko Hayashi, $\mathrm{PhD}^{1}$, \\ Kumpei Tokuyama, $\mathrm{PhD}^{1,3}$, Masashi Yanagisawa, MD, $\mathrm{PhD}^{1}$, Makoto Satoh, MD, $\mathrm{PhD}^{1}$ \\ IInternational Institute for Integrative Sleep Medicine (WPI-IIIS), 'Graduate School of Comprehensive Human Sciences, ${ }^{5}$ Ph.D Program in Human Biology, \\ University of Tsukuba, Tsukuba, Japan \\ ²Department of Somnology, Tokyo Medical University, Tokyo, Japan \\ ${ }^{4}$ Graduate School of Integrated Arts and Sciences, Hiroshima University, Hiroshima, Japan \\ ${ }^{6}$ Cardiovascular Respiratory Sleep Medicine, Juntendo University Graduate School of Medicine, Tokyo, Japan
}

\author{
Received: July 10, 2019 \\ Revised: October 17, 2019 \\ Accepted: November 14, 2019 \\ Correspondence \\ Makoto Satoh, MD, PhD \\ International Institute for \\ Integrative Sleep Medicine (WPI-IIIS), \\ University of Tsukuba, 1-2 Kasuga, \\ Tsukuba, Ibaraki, 305-8550, Japan \\ Tel +81-29-859-1858 \\ Fax +81-29-859-1290 \\ E-mailsatoh.makoto.fu@u.tsukuba.ac.jp
}

\section{ORCID}

Momoko Kayaba

https://orcid.org/0000-0002-3038-707X

Hitomi Ogata

https://orcid.org/0000-0002-7151-4733 Insung Park

https://orcid.org/0000-0001-6389-1937

Asuka Ishihara

https://orcid.org/0000-0001-9701-6284

Fusae Kawana

https://orcid.org/0000-0003-2227-0549

Toshio Kokubo

https://orcid.org/0000-0002-9098-3690

Shoji Fukusumi

https://orcid.org/0000-0002-0641-9799

Michiko Hayashi

https://orcid.org/0000-0002-2883-0757

Kumpei Tokuyama

https://orcid.org/0000-0003-1756-4227

Masashi Yanagisawa

https://orcid.org/0000-0002-7358-4022

Makoto Satoh

https://orcid.org/0000-0002-2723-8153
Background and Objective This study evaluated the effects of a mattress with better body pressure dispersal in comparison to a control mattress on sleep quality.

Methods In this randomized crossover study, 10 healthy young men slept in an experimental sleep room on either a functional mattress made from polyurethane, with a special four-layer three-dimensional structure, or a control mattress made from solid polyester wadding, which is a mattress commercially available in Japan. Polysomnography recordings were used to characterize sleep architecture, and the length of slow wave sleep (SWS) episodes and delta power density were calculated from the electroencephalography data and subjective sleep quality was evaluated by questionnaire they answered after waking.

Results There were no significant differences in sleep latency, the total duration of each sleep stages, total sleep time, or sleep efficiency. Although the difference was subtle, delta power density significantly increased with the functional mattress. There was no difference in the total duration of SWS, but there were significantly fewer SWS episodes with the functional mattress $(10.3 \pm 1.8)$ than with the control mattress $(16.9 \pm 1.2)$ and longer SWS episode duration $(10.9 \pm 1.7 \mathrm{~min})$ with the functional mattress than with the control mattress ( $5.6 \pm 0.5 \mathrm{~min})$.

Conclusions It was suggested that the functional mattress lengthened SWS episode duration, and its fragmentation was effective in evaluating the sleep quality of healthy young individuals.

Sleep Med Res 2019;10(2):75-82

Key Words Beds, Young adults, Polysomnography, Slow wave sleep.

\section{INTRODUCTION}

Over past few decades, the importance of sleep and its consequences on our health has gained greater recognition, in which sleep problems, such as insomnia, insufficient sleep and other sleep disorders, have become common in the modern society. There has been an extensive study in epidemiology and physiology on the aspects of individual's health and social status relating to sleep, in addition to sleeping environments, such as noise [1,2], light [3-5], thermal conditions [6], and other residential factors [7]. There has also been an increase in public interest on the sleeping environment, including the functions and materials used in the bedding systems [8].

Many previous studies that evaluated the effects of mattresses on sleep among healthy participants have lacked clarity in their descriptions of the nature of interventions performed and the methods used to evaluate sleep. Ambiguous terms, such as "soft," "firm," "comfort," and "dis- 
comfort" have been used to describe the different types of mattresses used [8-10], while some studies provided no detailed information about their mattresses [11,12], making experiments difficult to repeat. Other studies evaluated the effects of mattresses on pressure distribution and spinal distortion but did not measure sleep quality [13-16]. Studies that only used the questionnaires and/or actigraphy to assess sleep for different mattress conditions were unable to provide insights into the effects on the stages of sleep and sleep architecture $[8,10,17]$.

A limited number of studies have used polysomnography (PSG) to assess the effects of mattress condition on sleep architecture $[11,12,18]$. Focusing on the pressure distribution, Chen et al. [11] reported an association between the distribution of pressure over a mattress and the amount of slow wave sleep (SWS) and micro-arousals experienced. However, even though the general characteristics of the mattresses in this study were reported, there were no descriptions on the composition of each layer of the mattress, their thickness, or the specific differences between the mattresses. A study by Verhaert et al. [18] focusing on spinal alignment did not detect any difference in sleep stages between mattresses, although they reported that a "sagging" sleep system negatively affected sleep quality for people sleeping in a prone or lateral posture. Scharf et al. [12] found no significant differences between the mattresses in terms of sleep stages or number of wakes; however, the mattress conditions influenced cyclic alternating patterns, a reflection of the instability of sleep, indicating that the mattresses did have at least some influence on individuals' sleep. This suggested that measuring only the total duration of each sleep stage may not be sufficient to evaluate the effects of mild interventions, such as the uses in different mattresses, on the quality of sleep. Notably, sleep studies in rodents use episode duration as an index of the consolidation of non-rapid eye movement sleep (NREM) [19,20], which plays a significant role in increasing slow wave activity (SWA) $[21,22]$.

The present study aimed to evaluate differences in sleep between the functional mattress with better body pressure dispersal and the control mattress using the following parameters; the number of occurrences of each sleep stage throughout the night, and the duration of each sleep stage episode.

\section{METHODS}

\section{Design}

The experiment was conducted using a randomized crossover design to take account of individual variations in sleep.

\section{Participants}

Eleven healthy adult men were recruited. However, one failed to follow experimental instructions for his sleep schedule prior to the PSG test; thus, 10 participants completed the study. They were all nonsmokers, not on medication, none had a history or symptoms of sleep disorders or complaints about their sleep. The Morningness-Eveningness Questionnaire (MEQ) [23,24] was used to exclude anyone with an extreme morning or evening type. Habitual sleep quality was assessed using the validated Japanese edition of the Pittsburgh Sleep Quality Index (PSQI) [25,26]. The characteristics of the participants are presented in Table 1 . The range in age was from 21 years to 28 years, height from $167 \mathrm{~cm}$ to $181 \mathrm{~cm}$, weight from $53.8 \mathrm{~kg}$ to $88.1 \mathrm{~kg}$, body mass index from $18.6 \mathrm{~kg} / \mathrm{m}^{2}$ to $26.9 \mathrm{~kg} / \mathrm{m}^{2}$, and body fat from $7.4 \%$ to $21.4 \%$. The range in PSQI was from 2 to 11 , where five of the 10 participants had PSQI scores $\geq 6$, indicating poor sleep quality. The range in MEQ score was from 44 to 64 (i.e., from the neutral type to the moderate morningness type). Their habitual sleep duration, bedtime, and waking time were 7.0 \pm 1.3 h, 0:09 \pm 0:51, 7:36 \pm 0:57, respectively. According to the photographic record on their bedding environment, 9 out of 10 participants showed that they pile few thin mattresses to create their bedding. This study was approved by the Ethics Committee of the Faculty of Health and Sports Sciences at the University of Tsukuba (approval no. 27-32). Written informed consent was obtained from all participants.

\section{Procedures}

The participants were given detailed instructions on the procedures of the experiment. They were asked to maintain the same sleep schedule as the experiment night and avoid naps from 1 week prior to and throughout the study period, which was confirmed by a sleep sensor mat (Nemuri SCAN, PARAMOUNT BED Co., LTD., Tokyo, Japan) installed under the mattress at the participant's home. They were asked to avoid exercises and any consumption of alcohol and caffeine from 3 days prior to the experiment. They completed a self-reported sleep diary starting a week before the experiment, and submitted the data on sleep recordings taken from the sleep sensor mat. The night before the experiment day, participants were asked to sleep in the experimental room using the control mattress to adapt and to avoid any first night effect.

On the day leading up to the start of the experiment, partici-

Table 1. The characteristics of participants

\begin{tabular}{lc}
\hline \multicolumn{1}{c}{ Variables } & Values $(\mathrm{n}=10)$ \\
\hline Age $(\mathrm{yr})$ & $23.9 \pm 2.2$ \\
Height $(\mathrm{cm})$ & $173.2 \pm 4.0$ \\
Weight $(\mathrm{kg})$ & $72.5 \pm 9.7$ \\
Body mass index $\left(\mathrm{kg} / \mathrm{m}^{2}\right)$ & $24.1 \pm 2.5$ \\
Body fat $(\%)$ & $17.6 \pm 4.1$ \\
PSQI score & $6.3 \pm 3.4$ \\
MEQ score & $54.7 \pm 6.8$ \\
Habitual sleep duration $(\mathrm{h})$ & $7.0 \pm 1.3$ \\
\hline
\end{tabular}

Values are presented as mean \pm SD.

PSQI: Pittsburgh Sleep Quality Index, MEQ: Morningness-Eveningness Questionnaire. 
pants ate three meals at home, with the caloric intake and protein-fat-carbohydrate balance calculated according to their body weight [27]. To avoid any acute effects of food on sleep, the third meals was eaten $5 \mathrm{~h}$ prior to their habitual sleep time. Participants arrived at the laboratory $3 \mathrm{~h}$ before their habitual bedtime. The order of the mattresses were randomized. Before the sleep recordings started, they completed a short questionnaire about their impressions of the mattress. PSG recordings started at their habitual sleep time and continued for 8 hours.

The second PSG test using the other mattress was performed after the washout period of more than 2 nights but within 2 weeks to avoid any seasonal effects on sleep.

\section{Mattresses}

The functional mattress (\&Free Mattress SA.R, Nishikawa Sangyo Co., Ltd., Tokyo, Japan) was made from polyurethane, with a special four-layer three-dimensional structure which were expected to distribute the body pressure efficiently and to maintain certain body posture for balanced body support (Fig. 1, right). The control mattress was made from solid polyester wadding, which is a mattress commercially available in Japan (Fig. 1, left). The characteristics of these two mattresses are presented in Table 2. Apart from the experimental day, temporary distribution of body pressure was measured using an XSENSOR system (XSENSOR Technology Corporation, Calgary, Canada) under instruction of each sleeping posture for all participants. An example of

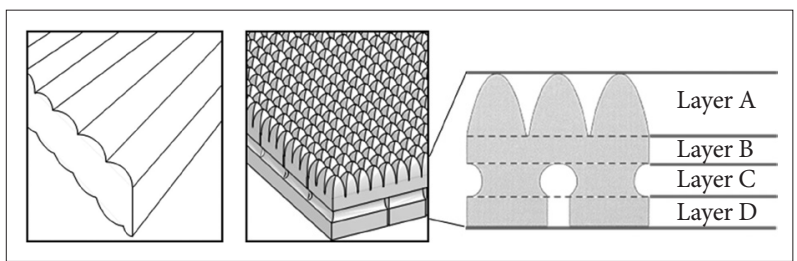

Fig. 1. Structure of control mattress (left) and functional mattress (right).

Table 2. The characteristics of mattresses

\begin{tabular}{lcc}
\hline & Control mattress & Functional mattress \\
\hline Structure & Corrugation & $\begin{array}{c}\text { Four-layered special } \\
\text { three-dimensional } \\
\text { structure }\end{array}$ \\
Thickness $(\mathrm{m})$ & 0.08 & 0.09 \\
Size $(\mathrm{m})$ & & \\
$\quad$ Length & 1.91 & 1.95 \\
$\quad$ Width & 0.91 & 0.97 \\
Material & Polyester solid wadding & Polyurethane \\
Density $\left(\mathrm{kg} / \mathrm{m}^{3}\right)$ & 49.8 & 36.5 \\
Hardness $(\mathrm{N})$ & 365 & 107 \\
Cover & Polyester $100 \%$ & Cotton $100 \%$ \\
\hline
\end{tabular}

Density and hardness were calculated conformed Japanese Industrial Standard. the distribution of body pressure with varying sleeping posture on the mattress is shown in Fig. 2. For all participants, the mean body pressure was lower on the functional mattress than on the control mattress in all postures (Table 3 ). In the pretest using the same blanket with each mattresses $(n=3)$, no differences in bedding climate [temperature and humidity were measured every 10 min using data logger (TR-72wf, T\&D Corporation, Matsumoto, Japan) and core body temperature was measured using CorTemp $^{\mathrm{TM}}$ (HQ Inc., Palmetto, USA)] between the mattresses were confirmed. Participants used the same pillow, blanket, and wore their habitual sleepwear in both conditions.

Prior to the electrode sensors, participants were asked to lie down on the mattress and complete a questionnaire on their impressions of the mattress, which had been constructed on the basis of a previous study [28]. The mattress was rated as follows: sensation of warmth or coldness (1, warm to 5, cold), stiffness (1, hard to 5 , soft), overall comfort (1, poor to 5 , excellent), humidity (1, humid to 5 , dry), comfort for the lower back (1, very bad to 7 , very good), comfort for the shoulder (1, very bad to 7 , very

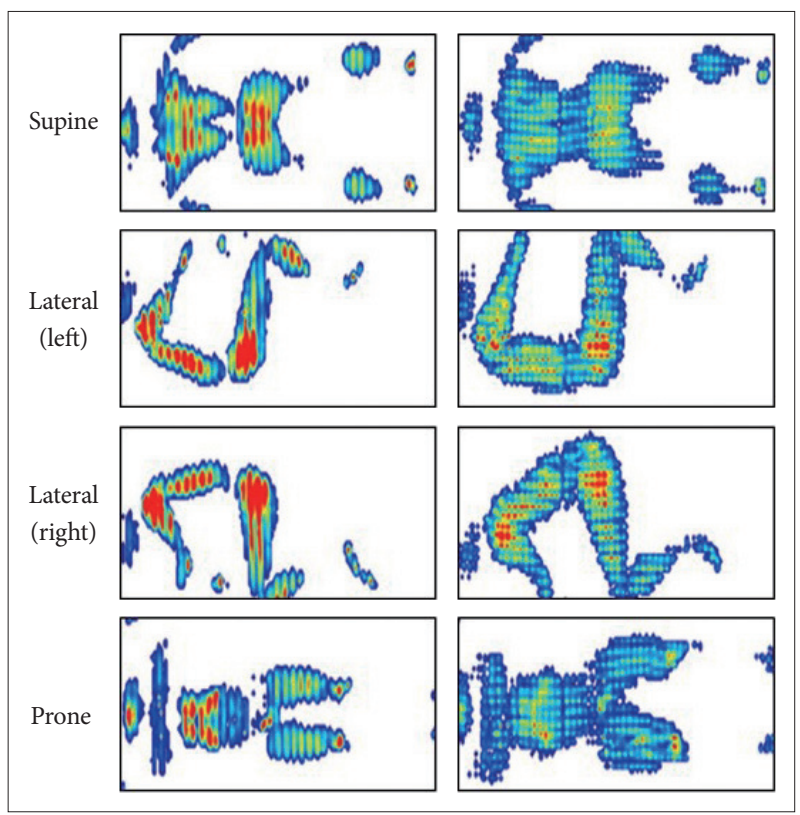

Fig. 2. Body pressure distribution in control mattress (left) and functional mattress (right). Body pressure distribution is shown as the gradations from blue (low pressure) to red (high pressure).

Table 3. Mean body pressure in each posture

\begin{tabular}{lccc}
\hline & $\begin{array}{c}\text { Functional } \\
\text { mattress }\end{array}$ & $\begin{array}{c}\text { Control } \\
\text { mattress }\end{array}$ & p value \\
\hline Supine $(\mathrm{mm} \mathrm{Hg})$ & $18.9 \pm 3.0$ & $24.1 \pm 5.2$ & $0.012^{*}$ \\
Lateral, right $(\mathrm{mm} \mathrm{Hg})$ & $22.5 \pm 3.6$ & $28.8 \pm 6.0$ & $0.012^{*}$ \\
Lateral, left $(\mathrm{mm} \mathrm{Hg})$ & $22.7 \pm 3.7$ & $29.7 \pm 5.6$ & $0.012^{*}$ \\
Prone $(\mathrm{mm} \mathrm{Hg})$ & $17.9 \pm 3.7$ & $21.5 \pm 5.2$ & $0.017^{*}$ \\
\hline
\end{tabular}

Values are presented as mean \pm SD. Data of 2 participants were missed due to mechanical failure $(n=8)$.

Significant differences were marked as ${ }^{*} \mathrm{p}<0.05$. 
good), comfort for the spine (1, very bad to 7, very good), comfort for normal sleeping when falling asleep (1, very bad to 7 , very good), ease of rolling over ( 1 , very difficult to 7 , very easy), and overall preference to the mattress (1, not preferred to 7 , highly preferred). Participants $(n=8)$ answered this questionnaire after waking in the following morning as well. The questionnaire results were used to analyze subjective impressions of mattresses from 8 participants who answered both in the night and in the morning.

\section{Sleep Recording and Measurements}

The participants slept in an experimental room (FHC-15S, Fuji Medical Science Co., Ltd., Chiba, Japan), in which the temperature and relative humidity were maintained at $25^{\circ} \mathrm{C}$ and $55 \%$, respectively, during sleep. PSG was conducted using Alice 5 PSG (Philips Respironics GK, Tokyo, Japan). This included six electroencephalography (EEG) channels, two electrooculography channels, an electromyography channels, and one body position sensor, which was fixed at the midline of the chest. The EEG electrodes were placed on the surface of the head in accordance with the International 10-20 system, recording at the frontal (F3, $\mathrm{F} 4)$, central $(\mathrm{C} 3, \mathrm{C} 4)$, and occipital $(\mathrm{O} 1, \mathrm{O} 2)$ sites, and at two reference sites on M1 and M2. EEG was recorded in 30-s epochs which was used to score sleep stages according to the standard criteria [29].

The C3-M2 EEG recording was sampled at $200 \mathrm{~Hz}$ and analyzed using discrete fast Fourier transform techniques, applying the transform to EEG record lengths of $5 \mathrm{~s}$ to obtain a frequency resolution of $0.2 \mathrm{~Hz}$. Each 5-s segment of the EEG signal was windowed with a Hanning tapering window prior to computing the power spectra. The power content (expressed in $\mu \mathrm{V}^{2}$ ) for each 30 -s epoch of sleep was determined as the average power across the six 5-s segments [30]. The spectral distribution was categorized into the following frequency bands: delta $(0.75-4.0 \mathrm{~Hz})$, theta $(4.1-8.0 \mathrm{~Hz})$, alpha $(8.1-12.0 \mathrm{~Hz})$, sigma $(12.1-14.0 \mathrm{~Hz})$, and beta $(14.1-30.0 \mathrm{~Hz})$. The delta power density was calculated as the delta power divided by the total power (over the range $0.75-30.0 \mathrm{~Hz}$ ) during NREM, expressed as a percentage.

For 8 hours, PSG recording was continued and participants were told to keep recumbent. However, some participants remained awake during the part of the last hour, which may have induced unclear situations of whether they woke up promptly or had to reluctantly go back to sleep. Therefore, sleep data for the first $7 \mathrm{~h}$ were used in the analysis.

After waking, the participants answered a questionnaire about their subjective sleep quality. The Oguri-Shirakawa-Azumi sleep inventory MA version (OSA-MA) was used to assess subjective sleep quality [31]. This questionnaire consists of 16 items with 5 factors ("Sleepiness on rising," "Initiation and maintenance of sleep," "Frequent dreaming," "Refreshness," and "Sleep length"), and these factors were standardized with a mean of 50 as their final scores.

\section{Statistical Analysis}

SWS episode duration and frequency was calculated from aforementioned stage of scored SWS. The Wilcoxon signed rank test was used to compare the data for the two mattresses. Threeway ANOVA was used to evaluate the short SWS episode duration, with the frequency of SWS episode duration as the response variable and mattress type, SWS episode duration, and participants as the predictor variables. The analyses were performed using SPSS ver. 22 (IBM Corp., Armonk, NY, USA). A p-value < 0.05 was considered statistically significant.

\section{RESULTS}

\section{Sleep Architecture and Stage Shifts}

Sleep architecture results are shown in Table 4. There was no significant difference between the mattresses in terms of sleep latency, rapid eye movement sleep (REM) latency, sleep efficiency, or the total duration of NREM1, NREM2, SWS, REM, and wake after sleep onset. The number of SWS episodes was significantly lower with the functional mattress $(10.3 \pm 1.8)$ than with the control mattress $(16.9 \pm 1.2)$. Difference in total number of stage shift between the two mattress conditions was not statistically significant ( $114.1 \pm 6.7$ vs. $126.9 \pm 6.8, \mathrm{p}=0.09)$, and number of stage shift was similar when stage shift from/to SWS was excluded $(101.3 \pm 5.6$ vs. $106.3 \pm 7.2, \mathrm{p}>0.3)$.

Table 4. Summary of polysomnography

\begin{tabular}{lccc}
\hline \multicolumn{1}{c}{ Sleep architecture } & $\begin{array}{c}\text { Functional } \\
\text { mattress }\end{array}$ & $\begin{array}{c}\text { Control } \\
\text { mattress }\end{array}$ & p value \\
\hline Sleep latency (min) & $6.3 \pm 1.4$ & $9.3 \pm 4.7$ & 0.779 \\
NREM1 (min) & $41.3 \pm 4.2$ & $37.5 \pm 3.6$ & 0.444 \\
NREM2 (min) & $198.9 \pm 8.2$ & $206.3 \pm 7.9$ & 0.386 \\
SWS (min) & $91.3 \pm 9.1$ & $94.5 \pm 7.8$ & 0.646 \\
REM (min) & $70.5 \pm 6.6$ & $65.0 \pm 5.3$ & 0.386 \\
WASO (min) & $7.5 \pm 4.6$ & $7.0 \pm 1.4$ & 0.400 \\
REM latency (min) & $139.1 \pm 16.0$ & $120.7 \pm 16.0$ & 0.646 \\
Arousal index & $1.5 \pm 0.5$ & $1.5 \pm 0.5$ & 0.887 \\
Sleep efficiency (\%) & $96.8 \pm 1.3$ & $97.1 \pm 1.4$ & 0.646 \\
Total stage shift (n) & $114.1 \pm 6.7$ & $126.9 \pm 6.8$ & 0.097 \\
NREM1 (n) & $40.2 \pm 2.3$ & $39.9 \pm 3.9$ & 0.720 \\
NREM2 (n) & $43.1 \pm 3.2$ & $48.7 \pm 3.5$ & 0.125 \\
SWS (n) & $10.3 \pm 1.8$ & $16.9 \pm 1.2$ & $0.022 *$ \\
REM (n) & $10.3 \pm 1.1$ & $11.0 \pm 1.2$ & 0.833 \\
WASO (n) & $11.2 \pm 1.4$ & $11.4 \pm 1.4$ & 0.876 \\
\hline
\end{tabular}

Values are presented as mean \pm SD $(n=10)$. Significant differences were marked as ${ }^{*} \mathrm{p}<0.05$.

NREM: non-rapid eye movement sleep, SWS: slow wave sleep, REM: rapid eye movement sleep, WASO: wake after sleep onset. 


\section{SWS Episode Duration}

Mean duration of SWS episode was $10.9 \pm 1.7$ min with the functional mattress as compared with $5.6 \pm 0.5 \mathrm{~min}$ with the control mattress. Distribution of SWS episode duration is shown in histogram (Fig. 3). Long SWS episode (especially more than $30 \mathrm{~min}$ ) was observed more during sleep in the functional mattress, and the number of SWS episodes lasting for just an epoch (30 s) was markedly decreased with the functional mattress compared to with the control mattress. The mean duration of SWS episodes was significantly longer with the functional mattress than with the control mattress $(p=0.013)$. Three-way ANOVA for the frequency of SWS episode durations in the range 0.5-5 min showed significant main effects of the mattress $[\mathrm{F}(1,153)=$ $11.6, p=0.001]$ and the SWS episode duration $[F(8,153)=24.1$, $\mathrm{p}<0.000$ ], as well as a significant interaction of mattress $\times$ SWS episode duration $[\mathrm{F}(8,153)=4.4, \mathrm{p}=0.003]$ (Fig. 4).

\section{Delta Power Density}

The delta power density was higher with the functional mattress than with the control mattress $(78.7 \% \pm 1.3 \%$ vs. $77.5 \% \pm$ $1.4 \%, \mathrm{p}=0.028$ ) (Fig. 5).

\section{Subjective Reports of Mattress and Sleep Quality}

In the questionnaire about the mattresses completed before sleep, participants scored the functional mattress as significantly softer than the control mattress $(p=0.017)$, with better overall feeling $(\mathrm{p}=0.034)$, greater comfort in the supine position $(\mathrm{p}=$ 0.023 ), and greater comfort in their habitual posture when falling asleep $(p=0.011)$. Responses after sleep showed that participants felt that the functional mattress was significantly softer $(\mathrm{p}=0.039)$ and provided greater comfort for the lower back ( $\mathrm{p}=$ 0.023 ) compared to the control mattress.

Regarding the subjective sleep quality, "Refreshness" was significantly better with the functional mattress $(50.5 \pm 4.1$ vs. 43.9 $\pm 7.3, \mathrm{p}=0.028$ ) while there were no differences between the two mattresses in "Sleepiness on rising," "Initiation and maintenance of sleep," "Frequent dreaming," and "Sleep length."

\section{DISCUSSION}

We observed that the functional mattress lengthened SWS episode duration. Better pressure distribution may have reduced discomfort at sites of compression on the body's surface, reducing the fragmentation of SWS. Chen et al. [11] reported that differences in pressure distribution of mattresses affected sleep. In the study, increase in SWS and the decrease in micro-arousals were observed in participants sleeping on pressure intermediately distributed mattress, compared to the ones that were overly-concentrated or overly-even in distribution of pressure [11]. In the present study, body pressures were actually lower with the functional mattress for all participants in every posture compared to the control mattress. Moreover, the functional mat-

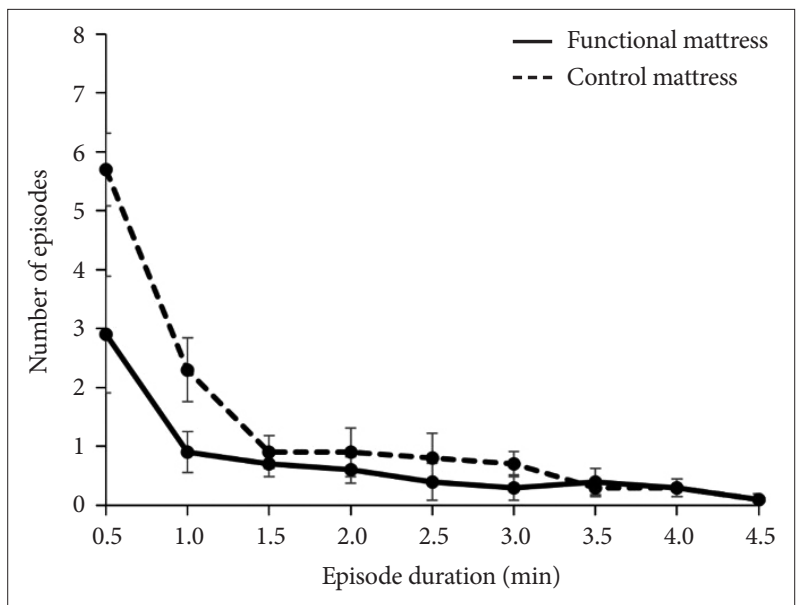

Fig. 4. Frequency of slow wave sleep episode duration under 5 $\min$.
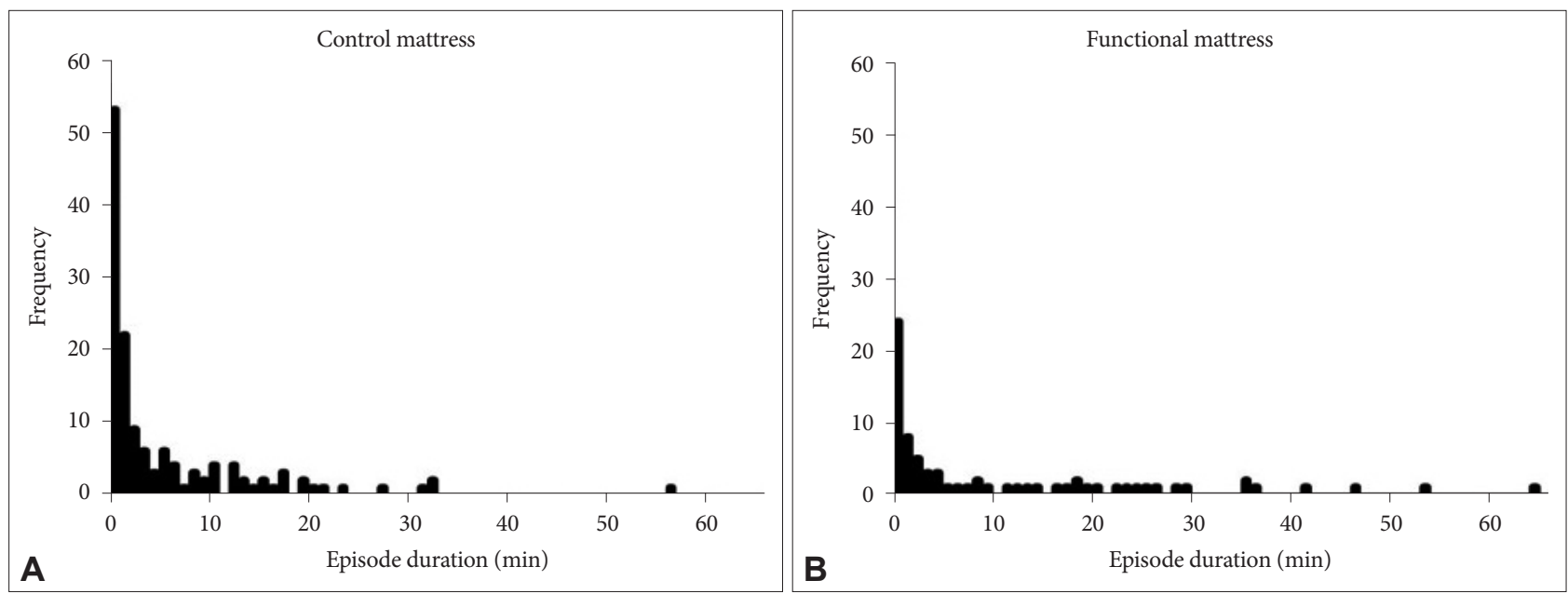

Fig. 3. Histogram of slow wave sleep episode duration with control mattress (A) and functional mattress (B). 


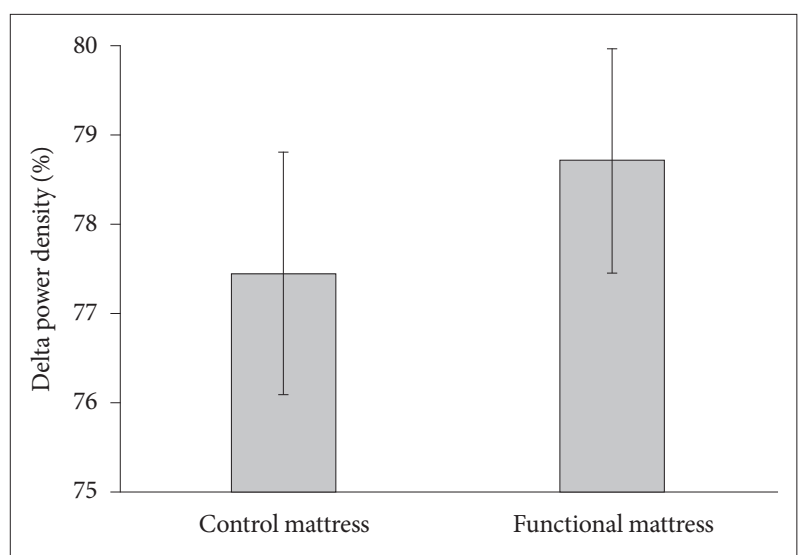

Fig. 5. Delta power density. Delta power density was expressed the percentage of delta power dividing by the total power (0.75$30.0 \mathrm{~Hz}$ ) during non-rapid eye movement sleep.

tress prevented over-sagging with its special four-layer threedimensional structure, which were expected to maintain a certain body posture for balanced body support. This suggested that body pressure distribution with the functional mattress was adequate for the sleep of healthy young adults. In addition to SWS episode duration, subjective sleep rating on "Refreshness" was improved with the functional mattress. The participants scored the functional mattress as softer and greater comfort for the lower back than the control mattress in the following morning. According to the previous study, medium-firm mattress had better outcome in patients with lower-back pain than with firm mattress [32]. The functional mattress with better body pressure distribution might be effective in providing comfort for the lower back and contributing to the feeling of improvement in "Refreshness" in the morning. Regarding other subjective sleep quality, there were no differences between the two mattresses in "Sleepiness on rising," "Initiation and maintenance of sleep," and "Frequent dreaming," which were in line with the PSG findings with no significant difference in the total duration of each sleep stages. The mean sleep latency was under $10 \mathrm{~min}$ for both mattresses, indicating that "Initiation and maintenance of sleep" might not have differed because of ceiling effects. "Sleep length" might not have differed because study design required sleep duration to be fixed. Thus, the functional mattress improved SWS episode duration and subjective feeling of "Refreshness." It is unlikely that the control mattress, which was harder than the functional mattress disturbed their sleep, because the sleep efficiency (approximately $97 \%$ for both mattress) was high in the present study. If sleeping on the control mattress was a negative intervention, sleep parameters might have deteriorated (e.g., increase in wake, decrease in sleep efficiency, prolonged sleep latency, etc.). Sleeping on the control mattress might rather have been a positive intervention because 9 out of 10 participants use only a few thin mattresses piled up at home.

As a potential novel parameter to evaluate sleep quality in healthy young participants, analysis of continuity of SWS episode was adopted in the present study. The following reasons can be cited as no difference in the major PSG parameters between the mattresses. Firstly, the participants of the present study were young healthy men and their sleep efficiency (approximately 97\% for both mattresses) was higher in the present study than the 80$93 \%$ efficiency reported in previous studies $[9,12,18]$, suggesting the ceiling effect. Secondly, intervention using a mattress was too subtle and did not change the whole night sleep dramatically. This is consistent with previous studies, which did not observe significant effects from different types of mattresses on the total duration of sleep stages $[12,18]$. However, we found that the number of SWS episode was significantly fewer with the functional mattress although delta power density and the total duration of SWS at night was almost the same between the two mattresses. Accordingly, we focused on the fragmentation of SWS, evaluated as episode duration. SWS episode duration was significantly longer, and the frequency of short SWS (0.5-1.0 min) decreased, with the functional mattress. In the polyphasic sleep pattern of rodents, peak delta power occurs minutes after the start of SWS [19], and the consolidation of NREM into longer duration is associated with an increase in SWA [20]. In this study, delta power density was significantly increased with the functional mattress but the differences in delta power density was subtle $(78.7 \%$ vs. $77.5 \%$ ). Taken together, we succeeded in evaluating difference in SWS, which was too small to reflect delta power density. Thus, the analysis of each duration of SWS episode provided greater insight into sleep quality than focusing on the total duration of SWS. SWA is related to important roles including growth hormone secretion [33,34], consolidation of memories [35], improving perceptual [36] and visuomotor performance [37], and continuity of sleep was suggested to be important for recuperation in the experiments with periodic sleep disruption in humans [38]. Therefore, SWS episode duration has a possibility in developing as a way to evaluate sleep in healthy young adults.

This study has some limitations. Although the participants controlled their life style and behavior as much as possible, evaluation of sleep quality and quantity prior to the experiment night were limited, and residential bedroom environment, including thermal, lighting and ambient noise condition, were not evaluated. However, the effect of personal and seasonal factors on sleep were minimized by the crossover design with relatively short duration between the trials in the present study. Secondly, REM latency was longer in both conditions. Although the reason was not clear and participants did not mention, there was a possibility that they were under stress in the experimental setting, even after one adaptation trial before the experiment. Thirdly, the sample size of the present study was small, thus larger numbers are required to generalize.

In conclusion, the functional mattress induced prolonged SWS episode duration, and improved "Refreshness" in subjective sleep quality. Intervention on sleep environment, which does not require daily personal efforts, would contribute to improving sleep 
and promoting health not only in symptomatic patients but also in overtly healthy people.

As a potential novel parameter, it was suggested that the fragmentation of SWS was effective in evaluating sleep quality in healthy young adults.

\section{Acknowledgments}

This study was financially supported by Nishikawa Sangyo Co., Ltd. This work was supported in part by World Premier International Research Center Initiative, MEXT, Japan.

We thank Masashi Furukawa, Yoji Shimura, and Saki Shimada of Nishikawa Sangyo Co., Ltd. who provided insight and expertise that greatly assisted the research, although they may not agree with all of the interpretations/ conclusions of this paper.

\section{Conflicts of Interest}

This study was financially supported by Nishikawa Sangyo Co., Ltd. MK and MS occasionally have given lectures on sleep physiology and hygiene at educational seminar supported by Nishikawa Sangyo Co., Ltd.

\section{Authors' Contribution}

Conceptualization: Kayaba M, Satoh M, Yanagisawa M, Tokuyama K, Kokubo T, Fukusumi S, Hayashi M. Data curation: Kayaba M. Formal analysis: Kayaba M, Ogata H. Funding acquisition: Kokubo T, Fukusumi S, Hayashi M. Investigation: Kayaba M, Park I, Ishihara A. Methodology: Kayaba M, Ogata H, Kawana F. Project administration: Satoh M, Yanagisawa M, Tokuyama K, Kokubo T. Resources: not applicable. Software: Ogata H. Supervision: Satoh M, Yanagisawa M, Tokuyama K, Kokubo T, Kawana F. Validation: not applicable. Visualization: Kayaba M. Writingoriginal draft: Kayaba M. Writing — review \& editing: Satoh M, Yanagisawa M, Tokuyama K, Kokubo T.

\section{REFERENCES}

1. Michaud DS, Feder K, Keith SE, Voicescu SA, Marro L, Than J, et al. Effects of wind turbine noise on self-reported and objective measures of sleep. Sleep 2016;39:97-109.

2. McGuire S, Müller U, Elmenhorst EM, Basner M. Inter-individual differences in the effects of aircraft noise on sleep fragmentation. Sleep 2016;39:1107-10.

3. Kayaba M, Iwayama K, Ogata H, Seya Y, Kiyono K, Satoh M, et al. The effect of nocturnal blue light exposure from light-emitting diodes on wakefulness and energy metabolism the following morning. Environ Health Prev Med 2014;19:354-61.

4. Marqueze EC, Vasconcelos S, Garefelt J, Skene DJ, Moreno CR, Lowden A. Natural light exposure, sleep and depression among day workers and shiftworkers at arctic and equatorial latitudes. PLoS One 2015;10: e0122078.

5. Chang AM, Scheer FA, Czeisler CA, Aeschbach D. Direct effects of light on alertness, vigilance, and the waking electroencephalogram in humans depend on prior light history. Sleep 2013;36:1239-46.

6. Haskell EH, Palca JW, Walker JM, Berger RJ, Heller HC. The effects of high and low ambient temperatures on human sleep stages. Electroencephalogr Clin Neurophysiol 1981;51:494-501.

7. Kayaba M, Ihara T, Kusaka H, Iizuka S, Miyamoto K, Honda Y. Association between sleep and residential environments in the summertime in Japan. Sleep Med 2014;15:556-64.

8. Jacobson BH, Gemmell HA, Hayes BM, Altena TS. Effectiveness of a selected bedding system on quality of sleep, low back pain, shoulder pain, and spine stiffness. J Manipulative Physiol Ther 2002;25:88-92.

9. Bader GG, Engdal S. The influence of bed firmness on sleep quality. Appl Ergon 2000;31:487-97.

10. Jacobson BH, Wallace T, Gemmell $\mathrm{H}$. Subjective rating of perceived back pain, stiffness and sleep quality following introduction of medium-firm bedding systems. J Chiropr Med 2006;5:128-34.

11. Chen Z, Li Y, Liu R, Gao D, Chen Q, Hu Z, et al. Effects of interface pressure distribution on human sleep quality. PLoS One 2014;9:e99969.

12. Scharf MB, Stover R, McDannold M, Kaye H, Berkowitz DV. Comparative effects of sleep on a standard mattress to an experimental foam surface on sleep architecture and CAP rates. Sleep 1997;20:1197-200.

13. Defloor T. The effect of position and mattress on interface pressure. Appl Nurs Res 2000;13:2-11.

14. Defloor T, De Schuijmer JD. Preventing pressure ulcers: an evaluation of four operating-table mattresses. Appl Nurs Res 2000;13:134-41.

15. Shelton F, Barnett R, Meyer E. Full-body interface pressure testing as a method for performance evaluation of clinical support surfaces. Appl Ergon 1998;29:491-7.

16. DeVocht JW, Wilder DG, Bandstra ER, Spratt KF. Biomechanical evaluation of four different mattresses. Appl Ergon 2006;37:297-304.

17. Tonetti L, Martoni M, Fabbri M, Natale V. Relationship between mattress technological features and sleep quality: an actigraphic study of healthy participants. Biological Rhythm Research 2011;42:247-54.

18. Verhaert V, Haex B, De Wilde T, Berckmans D, Verbraecken J, de Valck E, et al. Ergonomics in bed design: the effect of spinal alignment on sleep parameters. Ergonomics 2011;54:169-78.

19. Bjorness TE, Dale N, Mettlach G, Sonneborn A, Sahin B, Fienberg AA, et al. An adenosine-mediated glial-neuronal circuit for homeostatic sleep. J Neurosci 2016;36:3709-21.

20. Trachsel L, Tobler I, Achermann P, Borbély AA. Sleep continuity and the REM-nonREM cycle in the rat under baseline conditions and after sleep deprivation. Physiol Behav 1991;49:575-80.

21. Bjorness TE, Kelly CL, Gao T, Poffenberger V, Greene RW. Control and function of the homeostatic sleep response by adenosine A1 receptors. J Neurosci 20094;29:1267-76.

22. Suzuki A, Sinton CM, Greene RW, Yanagisawa M. Behavioral and biochemical dissociation of arousal and homeostatic sleep need influenced by prior wakeful experience in mice. Proc Natl Acad Sci U S A 2013;110:10288-93.

23. Horne JA, Ostberg O. A self-assessment questionnaire to determine morningness-eveningness in human circadian rhythms. Int $J$ Chronobiol 1976;4:97-110.

24. Ishihara K, Miyashita A, Inugami M, Fukuda K, Yamazaki K, Miyata Y. [The results of investigation by the Japanese version of MorningnessEveningness Questionnaire]. Shinrigaku Kenkyu 1986;57:87-91.

25. Buysse DJ, Reynolds CF 3rd, Monk TH, Berman SR, Kupfer DJ. The Pittsburgh Sleep Quality Index: a new instrument for psychiatric practice and research. Psychiatry Res 1989;28:193-213.

26. Doi Y, Minowa M, Uchiyama M, Okawa M. Development of the Japanese version of the Pittsburgh Sleep Quality Index. Jpn J Psychiatry Treat 1998;13:755-63.

27. National Institute of Health and Nutrition. Dietary reference intakes for Japanese 2010. Tokyo: Ministry of Health Labour and Welfare of Japan 2010.

28. Kogure T, Kubota T, Murayama R, Shinmura H. Mobility and comfort on a mattress influence sleep. Jpn J Physiol Anthropol 2011;16:171-6.

29. American Academy of Sleep Medicine. The AASM manual for the scoring of sleep and associated events summary of updates in version 2.3 [cited 2016 April 1]. Available from: http://www.aasmnet.org/Resources/pdf/ScoringManualUpdates_April_2016.pdf.

30. Zhang L, Samet J, Caffo B, Bankman I, Punjabi NM. Power spectral analysis of EEG activity during sleep in cigarette smokers. Chest 2008; 133:427-32.

31. Yamamoto Y, Tanaka H, Takase M, Yamazaki K, Azumi K, Shirakawa S. Standardization of revised version of OSA sleep inventory for middle age and aged. Brain Sci Ment Disord 1999;10:401-9.

32. Kovacs FM, Abraira V, Peña A, Martín-Rodríguez JG, Sánchez-Vera $M$, Ferrer E, et al. Effect of firmness of mattress on chronic non-specific low-back pain: randomised, double-blind, controlled, multicentre 
trial. Lancet 2003;362:1599-604.

33. Gronfier C, Luthringer R, Follenius M, Schaltenbrand N, Macher JP, Muzet A, et al. A quantitative evaluation of the relationships between growth hormone secretion and delta wave electroencephalographic activity during normal sleep and after enrichment in delta waves. Sleep 1996;19:817-24.

34. Van Cauter E, Copinschi G. Interrelationships between growth hormone and sleep. Growth Horm IGF Res 2000;10 Suppl B:S57-62.

35. Rasch B, Born J. About sleep's role in memory. Physiol Rev 2013;93:
681-766.

36. Aeschbach D, Cutler AJ, Ronda JM. A role for non-rapid-eye-movement sleep homeostasis in perceptual learning. J Neurosci 2008;28: 2766-72.

37. Landsness EC, Crupi D, Hulse BK, Peterson MJ, Huber R, Ansari H, et al. Sleep-dependent improvement in visuomotor learning: a causal role for slow waves. Sleep 2009;32:1273-84.

38. Bonnet MH. Effect of sleep disruption on sleep, performance, and mood. Sleep 1985;8:11-9. 